\title{
Application of chemotaxonomy of leafy spurges (Euphorbia spp.) in biological control
}

\author{
ANTONY N. G. HOLDEN and PAUL G. MAHLBERG \\ The authors are with the International Institute for Biocontrol, Silwood Park, Ascot, Berks, SL5 7TA, United Kingdom; \\ and Department of Biology, Indiana University, Bloomington, IN 47405, U.S.A., respectively,
}

\begin{abstract}
:
Triterpenoid profiles from latex of 56 accessions of European leafy spurges (Euphorbia spp.) were analyzed by gas-liquid chromatography. Qualitative and quantitative differences for components of the profiles were employed to distinguish between accessions. Triterpenoid profiles were diagnostic for the species, E. amygdaloides, E. agraria, E. cyparissias, E. lucida, and E. seguierana and were similar for each of these species in accessions collected from distant areas of Europe. By contrast, the 37 accessions of the E. esula complex were separated into 15 groups on qualitative and quantitative differences for components in the profiles. Identical profiles were detected among neighboring accessions as well as those in collections from widely distant sites; conversely, different profiles also were identified for such collections. Profiles among these groups were compared with profiles of 39 United States (U.S.) accessions of leafy spurge from Montana, Nebraska, North Dakota, and South Dakota. Profiles of U.S. accessions, which were less variable than those from Europe, grouped into only 3 of the 15 European groups, whereas one U.S. group could not be placed directly into a European group. This study demonstrates that latex analyses of European leafy spurges can distinguish between spurge populations and will identify potential plant sources of biocontrol agents for application against their leafy spurge counterparts in North America.
\end{abstract}

\section{Keywords:}

Leafy spurge, Euphorbia, latex, triterpenoids, gas-liquid chromatography. 


\section{Introduction}

Leafy spurge is a deep-rooted perennial with broad ecological tolerance introduced from Eurasia into North America where it is estimated to cover more than one million ha of rangeland (3).

Cultural and chemical control methods have proved expensive and largely ineffective (1). Consequently since the 1960s the potential of biological control agents, principally insects ( 7$)$ and more recently fungi $(2,4,13,15)$, has been investigated.

A classical biocontrol strategy relies on the introduction of a controlling agent present in the region from which the weed originated but absent where the weed has been introduced. Potential biocontrol agents must be sufficiently selective to exclude native species but broad enough to include hybrid forms of target plant (14). Host specific adaptation of a controlling agent may be most likely where the agent-weed association has been established for the longest time, presumably at the centre of origin of the weed. Reforming the association of agent and weed where the weed alone has been introduced depends on accurate identifications of plants in both the centre of origin and the target area.

Harris (7) and Watson (20) suggested that North American leafy spurge should not be considered as one species but rather as a complex of several very similar species. This complex is believed to originate from the species, Euphorbia esula L. and Euphorbia virgata Waldst. \& Kit. (as Euphorbia waldsteinii (Sojac)), but there is considerable morphological variability between members comprising the complex and identification is not easily achieved on morphological characteristics alone. Recently Crompton et al. (3), in a morphometric analysis on spurge material, concluded that leafy spurge should be considered as a single morphologically variable species, E. esula. Previous studies of cytotaxonomy $(12,17,18)$ and cytogenetics (19) also had indicated the close association between E. esula, E. virgata, and Euphorbia $\times$ pseudovirgata.

Resolving the identity of the target plant does not explain the biological incompatibility observed for certain potential biological agents, principally rusts, collected from $E$. esula in Europe that do not accept North American E. esula as a host plant. Laticifers, specialized cells within Euphorbia spp., contain triterpenoids in their latex that have been shown to be stable and can be interpreted as being typical for individual species $(9,10)$. Gas-liquid chromatographic analysis of these latex triterpenoids may aid in distinguishing between spurge taxa and therefore be relevant to the biocontrol programme through the characterization and comparison of latex triterpenoid profiles from European species with profiles obtained from North American accessions $(8,10)$. A close relationship between European and North American spurges should be indicated by similar profiles, and through these analyses it was hoped to assess those areas in Europe in which spurge plants might most successfully be surveyed for collection of biocontrol agents compatible with North American weedy species.

In this study we examined chromatographically the triterpenoid profiles of numerous spurge accessions collected in Europe with the following objectives: (I) to determine the range of variation of their profiles and (II) to compare them with the profiles of leafy spurge collections from several sites in the United States. 


\section{Materials and methods}

\section{Plant materials}

Rhizomes from populations of European leafy Euphorbia species (interpreted to include E. esula L., E. agraria Bieb., E. amygdaloides L., E. cyparissias L., E. lucida Waldst. \& Kit., and E. seguierana L.) were collected from six European countries during the summers of 1988 and 1989 (Table 1). Following collection, the rhizomes were grown at the International Institute of Biological Control (IIBC) with a 16-hour light: 8 hours dark regime and a temperature minimum of $16^{\circ} \mathrm{C}$. Plants were separated by morphological differences according to Radcliffe-Smith (16). Representative herbarium specimens have been prepared for reference and have been deposited at IIBC. Samples of latex from 39 United States (U.S.) leafy spurge accessions were collected at sites in four states, Montana (MT), Nebraska (NE), North Dakota (ND), and South Dakota (SD). Plants were marked in the field for subsequent collection and analyses.

Table 1. Source and profile groups of accessions.

\begin{tabular}{|c|c|c|c|c|c|}
\hline \multicolumn{3}{|c|}{ Europe } & \multicolumn{3}{|c|}{ United States } \\
\hline Source & $\begin{array}{c}\text { No. of } \\
\text { sites }\end{array}$ & Source & $\begin{array}{c}\text { No. of } \\
\text { sites }\end{array}$ & Source & $\begin{array}{c}\text { No. of } \\
\text { sites }\end{array}$ \\
\hline E. agraria & & Group F & & E. esula & \\
\hline Romania & 1 & Hungary (Pest) & 1 & Group US-A & \\
\hline E. amygdaloides & & Group G & & Montana & 3 \\
\hline Switzerland & 1 & Hungary (Csongrad) & 1 & North Dakota & 4 \\
\hline E. cyparissias & & Group H & & South Dakota & 2 \\
\hline Austria & 2 & Czechoslovakia & 1 & Group US-B & \\
\hline Hungary & 3 & Hungary (Hadjú-Bihar) & 1 & North Dakota & 3 \\
\hline E. lucida & & Group I & & Group US-C & \\
\hline Hungary & 1 & Hungary (Szloznak) & 1 & Nebraska & 5 \\
\hline E. seguierana & & Group J & & Group US-D & \\
\hline Germany & 1 & Hungary (Csongrad, & & Montana & 9 \\
\hline Hungary & 2 & Hadjú-Bihar) & 2 & North Dakota & 8 \\
\hline E. esula & & Group K & & South Dakota & 2 \\
\hline Group A & & Austria & 3 & & \\
\hline Hungary (Csongrad) & 1 & Group L & & & \\
\hline Group B & & Austria & 2 & & \\
\hline Hungary (Pest, Hadjú-Bihar) & 2 & Group M & & & \\
\hline Group C & & Austria & 2 & & \\
\hline Hungary (Csongrad) & 1 & Czechoslovakia & 1 & & \\
\hline Group D & & Group N & & & \\
\hline Hungary (Pest) & 1 & Austria & 1 & & \\
\hline Group E & & Group O & & & \\
\hline Hungary (Pest, Csongrad) & 2 & Czechoslovakia & 1 & & \\
\hline
\end{tabular}

Page 3 of 12 


\section{Gas-liquid chromatography}

Latex from the cut shoots of accessions was collected into individual acetone-washed vials. At least 10 drops of latex were collected from each plant. Plants were not destructively sampled. All of the European accessions analyzed are maintained as living populations at IIBC.

Vials were left open overnight to allow the latex sample to dry before being capped and stored at $4{ }^{\circ} \mathrm{C}$ prior to shipment to Bloomington, Indiana. On arrival the samples were frozen until analysis could be concluded.

Extraction and analysis of the samples has been described (10). The three triterpenoids identified previously (10), euphol, cycloartenol, and 24-methylene cycloartenol, can be related to profiles described in this study. Here, as in (10), the term triterpenoids is used to include free and acetate forms of sterols and triterpenes.

Collection sites and IIBC accession numbers included Austria: Kirchstetten 327 , Kleinkadolz 20, 22, 330, Krems 319, St. Poulten 1, 5, 6, 18, 291, 326, and Transmauer 4, 15, 16; Czechoslovakia: Cejkovice 17, 292, Nr. Brno 7, 328, Zigloviche 323; Germany (western) 27, 28; Hungary: Hajdú-Bihar 11, 12, 13, 21, 324, Bacs-Kiskun 286, 325, Csongrad 9, 10, 23, 288, 316, 322, Pest 2, 3, 14, 24, 26, 29, 30, 287, 290, 293, 294, 297 , 298, 318, 320, 329; Romania: Braila 295, 296, 317, Tulcea 8; Switzerland: Delémont 299, 300. Collections in U.S. included accessions of latex samples designated MT 211 224, NE 206-210, ND 001-015, and SD 201-205.

\section{Results}

The triterpenoid profiles were diagnostic for each taxon outside of E. esula (Table 2). Depending on the accession, the resulting profiles contained between four and nine peaks, each comprising more than $0.5 \%$ of the total triterpenoid content. The profiles were distinctive for different taxa, but two peaks, 12 and 13, were common to all the profiles including those from E. esula. Peak 7 was detected in all of the samples except those of $E$. amygdaloides, which was further separated by the presence of peak 1 not detected in the other profiles (Tables 2 and 3).

The profile of E. seguierana was distinguished by the presence of peak 3 not observed in any of the other accessions (Table 2).

The profile of E. lucida characteristically showed only four peaks, with peak 13 representing over $70 \%$ of the total triterpenoid content, although the presence of a shoulder indicated that this proportion included a small quantity of a second compound (Table 2).

The profile of E. cyparissias was composed of the same four peaks as in E. lucida (peaks 7, 10,12, and 13), but was separated because shoulders were associated with peaks 7, 10, and less obviously 13. Euphorbia cyparissias further differed from E. lucida in that peak 6 was detected in trace amounts, and peaks 12 and 13 represented similar proportions of the total triterpenoid content. The profile of E. agraria consisted of seven peaks, with peak 6 again present in trace amounts (Table 2). Although variation was observed within these species profiles, the proportions of triterpenoid components in the 
profile remained constant. Comparison of the profiles of latex collected from shoots in the field to latex from shoots of the same rhizome growing in the glasshouse showed them to be the same and confirmed the findings of Mahlberg et al. $(9,10)$ that environment does not modify the proportions of components within the profile.

In contrast with the stability of the profiles from E. agraria, E. amygdaloides, E. cyparissias, E. lucida, and E. seguierana, the 37 European E. esula accessions were separated into 15 different groups on the basis of qualitative and quantitative differences in triterpenoid contents (Table 3). Fifteen peaks were detected in the profiles from these accessions.

Groups A to E were separated by differences in the relative proportions of individual peaks (Fig. 1). In each group peak 13 (RT 16.90, Table 3) represented the major component of the triterpenoid content.

Group A comprised three accessions collected from one site in the Csongrad region of Hungary. Typically in these profiles peak 7 was present in lower proportion than peak 11. The presence of a peak to the right of peak 7 was indicated by an unmarked shoulder. Present, but less conspicuous, was an additional component on the left side of peak 11 (RT 15.27 in Fig. 1).

In accessions of group B peaks 7 and 11 were of similar proportion, and an extra peak, peak 9, possibly represented in group A as the less conspicuous shoulder to the left of peak 8 , was detected in trace amounts.

Group C was composed of one profile obtained from an accession collected in Csongrad. The profile was very similar to the profiles of group A, but it differed in that peak 14 comprised the second largest component of the profile rather than peak 12. A shoulder was present with peak 7 and peak 11 .

Profiles in which peak 7 comprised more than $10 \%$ of the total triterpenoid content, with a shoulder associated with the peak, were designated group D (Fig. 2). All three accessions included in this group were collected from one site in the Pest region of Hungary. Group E profiles, two accessions collected from the Csongrad and Pest regions of Hungary, were separated from previous groups by the presence of only a trace amount of peak 14.

Two further accessions collected in the Pest region, designated group F, were characterized by peak 7 representing over $20 \%$ of the total triterpenoid content, the presence of peak 9 , a peak unique to this group, and the increased proportion of peak 14 relative to peak 17 (Fig. 3). Only in this group, and group C, did peak 14 represent a greater proportion of the total triterpenoid content than peak 12 (Table 3).

Group $\mathrm{G}$ consisted of one accession collected from the same site as the accessions comprising group A, and only peak 7 was detectable only as a trace amount (Fig. 4). In contrast with previous groups peak 12 , rather than peak 13, represented the major component in the profile. This was one of only two groupings in which peak 13 was not the major proportion of the triterpenoid fraction. Only four peaks were represented in the profile (Table 3). Retention time (RT) values above 19.34 in the figure were not relevant to this study (Fig. 4).

Page 5 of 12 
Table 2. Percent composition of triterpenoid components in latex profiles of European spurge accessions

\begin{tabular}{|c|c|c|c|c|c|c|c|c|c|c|c|c|c|c|c|c|c|c|}
\hline $\begin{array}{r}\text { Peak No.: } \\
\text { RT: }\end{array}$ & $\begin{array}{c}1 \\
10.12 \\
\end{array}$ & $\begin{array}{c}2 \\
10.52 \\
\end{array}$ & $\begin{array}{c}3 \\
10.86 \\
\end{array}$ & $\begin{array}{c}4 \\
11.14 \\
\end{array}$ & $\begin{array}{c}5 \\
11.94 \\
\end{array}$ & $\begin{array}{c}6 \\
13.16 \\
\end{array}$ & $\begin{array}{c}7 \\
13.98 \\
\end{array}$ & $\begin{array}{c}8 \\
14.30 \\
\end{array}$ & $\begin{array}{c}9 \\
14.70 \\
\end{array}$ & $\begin{array}{c}10 \\
15.01 \\
\end{array}$ & $\begin{array}{c}11 \\
15.22 \\
\end{array}$ & $\begin{array}{c}12 \\
15.80 \\
\end{array}$ & $\begin{array}{c}13 \\
16.90 \\
\end{array}$ & $\begin{array}{c}14 \\
17.80 \\
\end{array}$ & $\begin{array}{c}15 \\
18.90 \\
\end{array}$ & $\begin{array}{c}16 \\
19.20 \\
\end{array}$ & $\begin{array}{c}17 \\
19.50 \\
\end{array}$ & $\begin{array}{c}18 \\
20.08 \\
\end{array}$ \\
\hline E. seguierana & - & - & $2 \pm 0.5$ & - & - & - & $12 \pm 1.0$ & $10 \pm 1.3$ & - & $6 \pm 2.1$ & $9 \pm 0.5$ & $39 \pm 3.2$ & $22 \pm 1.8$ & - & - & - & - & - \\
\hline E cypanssias & - & - & - & - & - & $\operatorname{tr}$ & $13 \pm 6.8$ & $4 \pm 0.6$ & - & $6 \pm 0.8$ & $9 \pm 1.0$ & $33 \pm 3.8$ & $35 \pm 7.7$ & - & - & - & - & - \\
\hline E. lucida & - & - & - & - & - & - & $14 \mathrm{~s} \pm 4.4$ & - & - & $4 \pm 0.5$ & - & $11 \pm 2.2$ & $71 \pm 2.6$ & - & - & - & - & - \\
\hline E. amygdaloides & $2 \pm 0.6$ & $\begin{array}{c}11 \pm \\
1.1\end{array}$ & - & - & $\operatorname{tr}$ & - & - & $3 \pm 0.5$ & - & - & $24 \pm 1.8$ & $29 \pm 0.9$ & $31 \pm 1.0$ & - & - & - & - & - \\
\hline E. agraria & - & - & - & - & - & $\operatorname{tr}$ & $3 \pm 0.5$ & $4 \pm 0.6$ & - & - & $9 \pm 0.8$ & $24 \pm 2.5$ & $56 \pm 1.3$ & - & - & - & $4 \pm 1.9$ & - \\
\hline
\end{tabular}

Note: Relative retention time was corrected to internal standard of $6.43 \mathrm{~min}$. for all chromatograms. tr, peaks comprising $<0.5 \%$ total triterpenoid content; - not detected.

Table 3. Percent composition of triterpenoid components in latex profiles of European leafy spurge accessions

\begin{tabular}{|c|c|c|c|c|c|c|c|c|c|c|c|c|c|c|c|c|c|c|}
\hline Peak No.: & 1 & 2 & 3 & 4 & 5 & 6 & 7 & 8 & 9 & 10 & 11 & 12 & 13 & 14 & 15 & 16 & 17 & 18 \\
\hline RT: & 10.12 & 10.52 & 10.86 & 11.14 & 11.94 & 13.16 & 13.98 & 14.30 & 14.70 & 15.01 & 15.22 & 15.80 & 16.90 & 17.80 & 18.90 & 19.20 & 19.50 & 20.08 \\
\hline Group A & - & - & - & - & - & - & $4 s \pm 0.9$ & - & - & - & $s 6 \pm 0.8$ & $25 \pm 3.0$ & $48 \pm 3.8$ & $17 \pm 4.6$ & - & - & - & - \\
\hline Group B & - & - & - & - & - & - & $4 \pm 1.2$ & - & - & - & $s 4 \pm 0.3$ & $33 \pm 0.9$ & $47 \pm 3.9$ & $12 \pm 0.6$ & - & - & - & - \\
\hline Group C & - & - & - & - & - & - & $3 s \pm 0.1$ & $\operatorname{tr}$ & - & - & $s 7 \pm 0.2$ & $17 \pm 0.4$ & $55 \pm 1.2$ & $18 \pm 0.6$ & - & - & - & - \\
\hline Group D & - & - & - & - & - & - & $12 s \pm 3.1$ & - & - & - & $s 2 \pm 1.1$ & $18 \pm 3.8$ & $58 \pm 6.7$ & $10 \pm 1.3$ & - & - & - & - \\
\hline Group E & - & - & - & - & - & - & $3 s \pm 0.6$ & - & - & - & $s 7 \pm 0.5$ & $26 \pm 0.8$ & $64 \pm 3.1$ & $\operatorname{tr}$ & - & - & - & - \\
\hline Group F & - & - & - & - & - & - & $21 s \pm 0.4$ & - & $5 \pm 0.2$ & - & $s 6 \pm 0.1$ & $14+0.8$ & $34 \pm 1.1$ & $20 \pm 2.0$ & - & - & - & - \\
\hline Group G & - & - & - & - & - & - & $\operatorname{tr}$ & - & - & - & $s 8 \pm 0.1$ & $43 \pm 0.1$ & $38+0.1$ & $11+0.1$ & - & - & - & - \\
\hline Group H & - & - & - & - & - & - & $1 s \pm 0.20$ & - & - & - & $s 6 \pm 0.6$ & $19 \pm 0.5$ & $59 \pm 1.1$ & $12 \pm 0.8$ & $2 \pm 3.4$ & - & $1 \pm 0.1$ & - \\
\hline Group I & - & - & - & - & - & - & $1 s \pm 0.2$ & - & - & - & $s 2+1.0$ & $17+3.3$ & $62 \pm 6.5$ & $17 \pm 0.5$ & - & - & $1 \pm 0.6$ & - \\
\hline Group J & - & $2 \pm 0.4$ & - & - & - & - & $3 \pm 0.8$ & $1 \pm 0.1$ & - & - & $s 6 \pm 2.7$ & $45 \pm 5.5$ & $36+7.0$ & $7 \pm 0.8$ & - & - & - & - \\
\hline Group K & - & $6 \pm 1.9$ & - & $\operatorname{tr}$ & - & - & - & - & - & - & - & - & $47 \pm 1.6$ & - & - & - & - & - \\
\hline Group L & - & $8 \pm 3.0$ & - & $\operatorname{tr}$ & - & - & $s 7 \pm 1.6$ & $7 \pm 1.1$ & - & - & $s 14 \pm 3.5$ & $26+2.5$ & $38 \pm 4.4$ & - & - & - & - & - \\
\hline Group M & - & $10 \pm 4.1$ & - & $2 \pm 0.8$ & - & $1 \pm 1.0$ & \{ & $18 \pm 6.1\}$ & - & \{ & $12+7.2)\}$ & $22 \pm 3.3$ & $32 \pm 3.9$ & - & - & $1 \pm 0.8$ & - & $3 \pm 3.0$ \\
\hline Group N & - & $13 \pm 2.6$ & - & $2 \pm 0.4$ & - & - & $6 s \pm 1.5$ & - & - & $4 \pm 1.1$ & $3 \pm 0.8$ & $22 \pm 0.1$ & $44 \pm 2.6$ & - & - & $3 \pm 0.9$ & - & - \\
\hline Group $\mathrm{O}$ & - & $8 \pm 4.1$ & - & $1 \pm 0.5$ & - & - & $2 \pm 1.2$ & $6 \pm 1.8$ & - & $4 s \pm 1.0$ & - & $30 \pm 3.5$ & $49 \pm 3.6$ & - & - & - & - & - \\
\hline
\end{tabular}

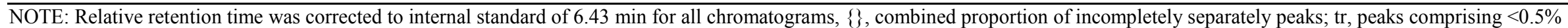
total triterpenoid content; -, not detected; $s$, shoulder associated with peak indicating position relative to peak. 


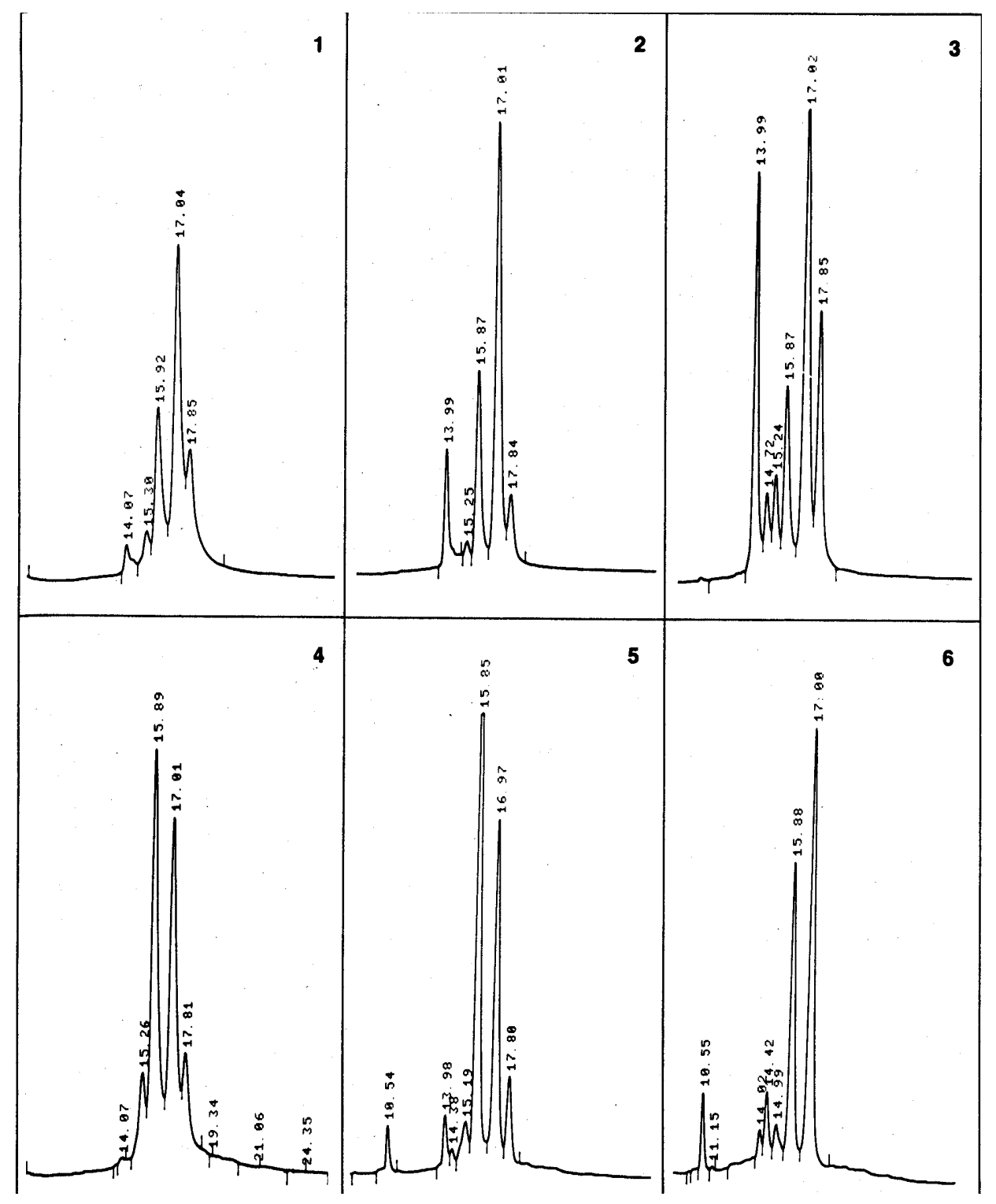

Figs. 1 - 6. Triterpenoid profiles from latex of European spurge accessions. Fig. 1. Group A profile showing five peaks marked by RT values Ed a trace of an unmarked component evident as a shoulder to right of RT 14.07. Peak 13 (RT 17.04) is the most abundant component. Fig. 2. Cioup D profile showing same five peaks as in group A, including shoulder for component to right of RT 13.99. Peak 13 (RT 17.01) is the MOst abundant component. Other peaks occur in a different ratio than in group A. Fig. 3. Group F profile showing same peaks as in $A$ and $E \sim$ but in a different ratio to those in $A$ and D. Peak 7 (RT 13.99) is the most prominent in the profile. Fig. 4. Group J profile showing peak $\sim(\mathrm{RT} 15.89)$ as the most abundant component rather than RT 17.0 1, as in groups A, D, and F. Peak 7 (RT 14.07) is very low in quantity, $Q$ peak 8 is not detectable. Fig. 5. Group $M$ profile showing presence of seven peaks including new components, peaks 2 (RT 10.54) and I (RT 14.38), compared with five peaks included in previous groups. Peak 12 (RT 15.85) is the most prominent component. Fig. 6. Group $O$ Profile showing presence of two new peaks, 2 and 8 (RT 10.55 and RT 14.38, respectively), in addition to peak 4 (RT 11. 15). In this profile Rlak 13 (RT 17.00) is the ost prominent component. 
Groups H and I were separated from groups A - F by the presence of peak 17 (Table 3). Group $H$ was separated from group I by the greater concentration of peak 14 in group I. The shoulders described for peak 7 and 11 in group A were evident in groups $\mathrm{H}$ and I, although one shoulder was very small in group $\mathrm{H}$. Three accessions of E. agraria from eastern Romania also showed peak 17 within the profile but were distinguished from groups $\mathrm{H}$ and I, collected in the Hadjú-Bihar region of Hungary and in southern Czechoslovakia, by the presence of peak 8 and trace amounts of compound 6 , whereas peak 14 was not detected.

Groups J (Fig. 5) and K included six accessions with profiles distinctly different from those of the previous nine groups. A new component, peak 2, was detected in both groups, and as for E. agraria, peak 8 was present in greater than trace amounts. Peak 8 represented the shoulder on the right side of peak 7 .

In group J peak 12, rather than peak 13, represented the largest component in the profile. Group J was separated from group $\mathrm{K}$ by the presence of peaks 7 and 14, which were not detected in group $\mathrm{K}$, whereas peak 4 was not detected in group J. In group K peak 13 was the most abundant component rather than peak 12. Group K possessed peaks 4 and 10 that were not detected in group J. Peak 10 also was detected as a shoulder associated with peak 11 in groups A and E. Characteristically, the profile of plants in group K included a pair of closely spaced peaks (peaks 10 and 11).

Groups L to O (Fig. 6) were characterized by the presence of peak 2, whereas peak 14 was not detectable. They were distinguished from each other by qualitative differences for peaks 7, 11, and 16 (Table 3). The profile of group $\mathrm{O}$ closely resembled that of group L but was separated on quantitative differences between peaks 7 and 13, and a shoulder associated with peak 10 in group $O$. The percent composition of peak 2 was greater in groups $\mathrm{M}$ and $\mathrm{N}$ than in groups $\mathrm{L}$ and $\mathrm{O}$.

The profiles from United States E. esula accessions were less variable than those from Europe, and the 37 accessions produced four profile types (Table 4).

Table 4. Percent composition of triterpenoid components in latex profiles of North America leafy spurge accessions.

\begin{tabular}{|c|c|c|c|c|c|c|c|c|c|c|c|c|c|c|c|c|c|c|}
\hline $\begin{array}{l}\text { Peak } \\
\text { No. }\end{array}$ & 1 & 2 & 3 & 4 & 5 & 6 & 7 & 8 & 9 & 10 & 11 & 12 & 13 & 14 & 15 & 16 & 17 & 18 \\
\hline RT: & 10.12 & 10.52 & 10.86 & 11.14 & 11.94 & 13.16 & 13.98 & 14.30 & 14.70 & 15.01 & 15.22 & 15.80 & 16.90 & 17.80 & 18.90 & 19.20 & 19.50 & 20.08 \\
\hline US-A & - & - & - & - & - & - & $1 \pm 0.2$ & $1 \pm 0.2$ & - & - & $\mathrm{s} 7 \pm 1.7$ & $30+4.8$ & $52 \pm 4.6$ & $10 \pm 2.7$ & - & - & - & - \\
\hline US-B & - & - & - & - & - & - & $\operatorname{tr}$ & $1 \pm 0.1$ & - & - & $\mathrm{s} 5 \pm 0.5$ & $25 \pm 1.4$ & $59 \pm 1.7$ & $10 \pm 1.9$ & - & - & - & - \\
\hline US-C & - & - & - & - & - & - & $5 \pm 0.8$ & $1 \pm 0.2$ & - & - & $\mathrm{s} 4 \pm 1.4$ & $27 \pm 2.1$ & $57 \pm 4.6$ & $6 \pm 0.2$ & - & - & - & - \\
\hline US-D & - & - & - & - & - & - & $2 \pm 1.1$ & $\operatorname{tr}$ & - & - & $\mathrm{s} 8 \pm 1.9$ & $28 \pm 4.0$ & $55 \pm 5.2$ & $7 \pm 2.0$ & - & - & - & - \\
\hline
\end{tabular}

Profile type US-A included nine samples detected at several sites in MT, ND, and SD (Table 4). The profile was separated by possessing similar proportions of peaks 7 and 8 
compared with group US-B that contained a greater proportion of peak 8 than peak 7 . Group US-B was collected only in Barnes County, MT, as were several samples of group US-A. Profiles in which peak 7 represented an increased proportion of the total triterpenoid content, and a greater concentration than peak 11, were assigned to group US-C (Table 4). The five latex samples from Rock County, NE characterized the group US-C profile. For these three groups peak 14 was greater than peak 11. Group US-D possessed a greater proportion of peak 7 to peak 8 and a greater proportion of peak 8 to peak 14 . Representative of the 17 accessions in group US-D predominated in MT and ND, along with two samples detected in SD. All US groups possessed a similar ratio of peaks 12 to 13, in which peak 12 was less than peak 13.

The profiles of European group A matched those of group US-A present in MT, ND, and SD. The three representatives of group US-B, with the ratio of peak 7 less than peak 8, did not match any European group. European group D, in which peak 7 exceeded peak 11 , had its counterpart in group US-C. European group E closely resembled group US-D.

\section{Discussion}

The use of morphological characteristics alone to distinguish leafy spurge species was shown by Ebke and McCarty (5) and Harvey et al. (8) to be of only limited value in the identification of leafy spurge, subsequently described by Crompton et al. (3) and Stahevitch et al. (19) to be E. esula. Mahlberg et al. $(9,10,11)$ demonstrated that the triterpenoid profile could be diagnostic for given taxa within the Euphorbiaceae and considered the potential value of triterpenoid analysis to the identification of plants of the E. esula complex.

The profiles reported here from the five species not of the E. esula complex are distinctive for individual species and appear to be relatively stable irrespective of the location from which the collection was made.

The stability of the profiles produced by other Euphorbia species under diverse growth conditions $(9,10,11)$ and from various sources indicates a genetic basis for triterpenoid synthesis and supports an interpretation that both qualitative and quantitative differences must be considered in the characterization of profiles. That the wide range of profile types for the E. esula accessions could not have been predicted merely from morphological characteristics lends support to the proposal by Harris (7) and Watson (20) that leafy spurge should be considered as a complex possibly consisting of biotypes. The identification of chemotypes and the separation of chemical profiles demonstrated here should enable local screening of individual European chemotaxa for biological control agents.

A recent report by Evans et al. (6) separated three forms of E. esula by analytical pyrolysis-pattern recognition. In our study we have identified further variation within the species and we describe both the similarities and differences for profiles from different populations of U.S. and European E. esula. European groups can be separated broadly into those lacking a detectable peak 2 (RT 10.52) (groups A-I) and those possessing this peak (groups J-O) irrespective of gross morphology. Additional qualitative and quantitative differences distinguish between the different groups. Mahlberg et al. (10) reported

Page 9 of 12 
that some quantitative variation for common peaks was evident in a cloned accession. The degree of variation demonstrated within that clone was of a similar magnitude to that detected within the groups reported here. Certain quantitative variations reported here in collections from individual locations may reflect differences within clones, as exemplified for peaks 7 and 14 in European groups A and C, or from groups US-A and US-D in MT and ND.

The factors that determine both the quantitative and qualitative differences between spurges are as yet unresolved (10). Mahlberg et al. (10) identified three of the components within the profile, peaks 7, 11, and 13, representing euphol, cycloartenol, and 24methylene cycloartenol, respectively. These components represent compounds in the profiles detected in this study. Mass spectroscopy of the remaining compounds is yet to be done. The objectives of this study are to determine the range of variation of triterpenoid profiles in European accession for comparison with accessions in the U.S., and we demonstrated these objectives. The identity of each component is not paramount in the present study and therefore does not detract from the value of the profiles as chemical markers by which it is possible to match plants from geographically diverse populations.

European populations showed greater variability in the number of triterpenoids present in the latex than has been detected in North American collections of leafy spurge, although analysis of European E. esula collected from one location can possess a profile identical to that for an accession from distant and unrelated sites. The relatively limited variation shown by profiles of examined North American accessions supports an interpretation that the adventive populations may be represented historically by a small number of introductions.

The possibility that biotypes exist within the leafy spurge E. esula populations of Europe and North America necessitates making collections from those plants in Europe that most closely resemble a particular North American type and targeting releases of biocontrol agents to areas in North America with an infestation of a plant type with comparable triterpenoid profiles. This study has provided information on the variation within European leafy spurges and will be applicable to identifying those sites in Europe where the plants may most closely resemble North American target plants. Profiles of group US-A matched those designated as European group A from the Pest region of Hungary. Similarities also were observed between collections from Pest and both US-C from NE and US-D from MT, ND, and SD, although the profiles from these collections did not match completely.

The implication of matching triterpenoid profiles of European with U.S. leafy spurge is that collections of natural enemies from certain separate sites at Pest and Csongrad may be most compatible with plants in MT, ND, and SD. Collections from separate sites in the Pest region of Hungary may most readily establish on weedy spurges in NE. Conversely, biocontrol agents collected from European leafy spurges differing qualitatively for triterpenoid components may be less compatible or incompatible with U.S. leafy spurges of dissimilar composition.

Profiles of E. agraria collected in eastern Romania did not correspond to profiles from plants in the United States, but similarities did exist. Similarly, collections of $E$.

Page 10 of 12 
esula from southern Czechoslovakia yielded profiles that have not as yet been observed in the United States.

Mahlberg et al. (10) reported that plants from Baker County, OR had a profile that included peak 2, although none of the North American accessions examined here showed this character. The OR profile most closely resembles those assigned here to group $\mathrm{M}$, but the relative proportions of peaks 7 and 8 were reversed in the European accessions compared with the Baker County accession, and peak 11 was associated with a distinct shoulder. However, the profile type with a peak at RT 10.52 (peak 2) does not appear to be widely distributed in the United States at present, and consequently collections of biocontrol agents made from the broader leaved European $E$. esula type may not readily accept the North American plants.

That certain profiles reported here resemble those of North American accessions could indicate that the North American plants may not represent an entirely new genotype derived by hybridization between introduced European E. esula and native North American spurges. Consequently, even if the North American weedy species are not direct descendants of the European introductions, the relationship appears close enough not to preclude European predators and (or) diseases from accepting the North American target plants as hosts.

The taxonomic significance and genetic origins of the latex triterpenoid content in plants of the E. esula complex, for the present, is not yet known. Importantly, the knowledge that spurge biotypes can be identified by latex triterpenoid profiles will facilitate interpretation of the host-pathogen interactions within the complex and should stimulate the search for virulent fungal strains or other biocontrol agents compatible with individual spurge types. Having established that different forms of E. esula occur throughout Europe, this technique is currently being employed to investigate the extent of variation in profile forms within individual sites in Canada and Europe.

\section{Acknowledgements}

The authors acknowledge the support of the following organizations: Alberta Ministry of Agriculture, Canadian Department of National Defense, Ministry of Agriculture of North Dakota, Montana State University, and Saskatchewan Agricultural Development Fund to A.N.G.H., and the National Science Foundation (8822562), United States Department of Agriculture personnel, and USDA (APH1234410185) to P.G.M.

\section{Literature cited}

1. Alley, H.P., and Messersmith, C.G. 1985. Chemical control of leafy spurge. In Leafy spurge. Edited by A.K. Watson. Weed Science Society of America, Champaign, Ill. pp. 65-79.

2. Bruckart, W.L., Turner, and S.K., Sutker, E.M., et al. 1986. Relative virulence of Melampsora euphoribae from central Europe toward North American and European spurges. Plant Dis. 70:847-850.

3. Crompton, C.W., Stahevitch, A.E., and Wojtas, W.A. 1990. Morphometric studies of the Euphorbia esula group (Euphorbiaceae) in North America. Can. J. Bot. 68:1978-1988.

Page 11 of 12 
4. Defago, G., Kern, H., and Sedler, L. 1985. Potential control of weedy spurges by the rust Uromyces scutellatus. Weed Sci. 31:866-873.

5. Ebke, D., and McCarty, M. 1983. A nursery study of leafy spurge (Euphorbia spp.) complex from North America. Weed Sci. 31:866-873.

6. Evans, J.O., Torell, J.M., Valcarce, R.V., and Smith, G.G. 1991. Analytical pyrolysis-pattern recognition for the characterization of leafy spurge (Euphorbia esula L.) biotypes. Ann. Appl. Biol. 119:4758 .

7. Harris, P. 1984. Euphorbia esula-virgata complex, leafy spurge and E. cyparissias L., cypress spurge (Euphorbiaceae). In Biological control programmes against insects and weeds in Canada, 1969-1980. Edited by J.S. Kelleher and M.A. Hulme. Commonwealth Agricultural Bureaux, Slough, England. pp. 159-169.

8. Harvey, S.J., Nowierski, R.M., Mahlberg, P.G., and Story,J.M. 1988. Taxonomic evaluation of leaf and latex variability of leafy spurge (Euphorbia spp.) for Montana and European accessions. Weed Sci. 36:726-733.

9. Mahlberg, P.G., Pleszczynska, J., Rauh, H.W., and Schnepf, E. 1983. Evolution of succulent Euphorbia as interpreted from latex composition. Bothalia, 14:533-539.

10. Mahlberg, P.G., Davis, D.G., Galitz, D.S., and Manners, G.D. 1987. Laticifers and the classification of Euphorbia: the chemotaxonomy of Euphorbia esula L. Bot. J. Linn. Soc. 94:165-180.

11. Mahlberg, P.G., Pleszczynska, J., and Furr, M. 1988. Comparison of latex triterpenoid profiles between normal and cristata taxa of Euphorbia and their chemotaxonomic implications. Monogr. Syst. Bot. 25:623-629.

12. Moore, R. J. 1958. Cytotaxonomy of Euphorbia esula in Canada and its hybrids with Euphorbia cyparissias. Can. J. Bot. 36:547-559.

13. Mortensen, K. 1984. Occurrence of fungi on leafy spurge in the prairie provinces from 1981-1983. Can. Dis. Surv. 64:43-48.

14. Pemberton, R.W. 1984. Native considerations in the biological control of leafy spurge. In Proceedings of the 6th International Symposium on Biological Control of Weeds, Vancouver, B.C., August 19-25, 1984. Agriculture Canada, Ottawa.

15. Pemberton, R.W., and Wang, R. 1989. Survey for natural enemies of Euphorbia esula L. in Northern China and Inner Mongolia. Chin. J. Biol. Contrib. 5:64-67.

16. Radcliffe-Smith, A. 1985. Taxonomy of North American leafy spurge. In Leafy spurge. Edited by A.K. Watson. Weed Science Society of America, Champaign, Ill. pp. 14-25.

17. Schulz-Schaeffer, J., and Gerhardt, S. 1987. Cytotaxonomic analysis of the Euphorbia spp. ("leafy spurge") complex. Biol. Zentralbl. 106:429-438.

18. Schulz-Schaeffer, J., and Gerhardt, S. 1989. Cytotaxonomic analysis of the Euphorbia spp. ("leafy spurge") complex. II. Comparative study of the chromosome morphology. Biol. Zentralbl. 108:64-76.

19. Stahevitch, A.E., Crompton, C.W., and Wojtas, W.A. 1988. Cytogenetic studies of leafy spurge, Euphorbia esula, and its allies (Euphorbiaceae). Can. J. Bot. 66:2247-2257.

20. Watson, A.K. 1985. The leafy spurge problem. In Leafy spurge. Edited by A.K. Watson. Weed Science Society of America, Champaign, Ill. pp. 1-6. 